University of Warwick institutional repository: http://go.warwick.ac.uk/wrap This paper is made available online in accordance with publisher policies. Please scroll down to view the document itself. Please refer to the repository record for this item and our policy information available from the repository home page for further information.

To see the final version of this paper please visit the publisher's website. Access to the published version may require a subscription.

Author(s): John P. CLARKSON, John STAVELEY, Kath PHELPS, Caroline S. YOUNG and John M. WHIPPS

Article Title: Ascospore release and survival in Sclerotinia sclerotiorum Year of publication: 2003

Link to published version: http://dx.doi.org/10.1017/S0953756203007159

Publisher statement: None 


\title{
Ascospore release and survival in Sclerotinia sclerotiorum
}

\author{
John P. CLARKSON ${ }^{1 *}$, John STAVELEY ${ }^{2}$, Kath PHELPS ${ }^{1}$, Caroline S. YOUNG ${ }^{3}$ and John M. WHIPPS \\ ${ }^{1}$ Horticulture Research International, Wellesbourne, Warwick CV35 9EF, UK. \\ ${ }^{2}$ Department of Applied Sciences, Geography and Archaeology, University College Worcester, Henwick Grove, \\ Worcester WR2 6AJ, UK. \\ ${ }^{3}$ ADAS Consulting Ltd, ADAS Wolverhampton, 'Woodthorne', Wergs Road, Wolverhampton WV6 8TQ, UK. \\ E-mail:john.clarkson@hri.ac.uk
}

Received 8 October 2002; accepted 16 December 2002.

The release and survival of ascospores of a UK Sclerotinia sclerotiorum isolate were studied. Apothecia placed in a spore clock apparatus with different lighting regimes at $15^{\circ} \mathrm{C}$ released ascospores continuously with an increasing rate for the duration of experiments $(72-84 \mathrm{~h})$. Spore release was not confined to light or dark periods in alternating regimes and occurred in continuous dark or light. Ascospores were released in both saturated air (90-95\% rh) and at $65-75 \% \mathrm{rh}$. High temperature and rh were detrimental to ascospore survival but spore viability was maintained for longer periods than previously reported. The significance of these results in relation to disease control is discussed.

\section{INTRODUCTION}

Sclerotinia sclerotiorum is a nectrotrophic pathogen with worldwide distribution known to infect over 400 species of plants (Boland \& Hall 1994). Important crops affected include oilseed rape, sunflower, tobacco and a range of vegetables such as lettuce, bean, cabbage, cauliflower, carrot and potato as well as a number of flower crops. The epidemiology of S. sclerotiorum has been investigated for a number of crops, particularly bean and oilseed rape (canola) (Abawi \& Grogan 1979, Boland \& Hall 1987) where ascospores are the primary infection source. Ascospores are released by apothecia which develop following carpogenic germination of sclerotia at or near the soil surface. Studies have shown that environmental factors governing sclerotial germination and development of apothecia include soil temperature, soil moisture and light (Phillips 1987, Bardin \& Huang 2001). Ascospores require wetness for germination and infection, with senescent tissues generally serving as a nutrient source for subsequent disease development (Bardin \& Huang 2001).

In contrast with the information available on carpogenic germination of sclerotia, there are few studies on the effect of environmental factors on

\footnotetext{
* Corresponding author.
}

S. sclerotiorum ascospore release and survival, despite these being potentially important factors in the life cycle of the pathogen and the development of disease. The structure and development of the apothecium of S. sclerotiorum, however, has been well documented (Saito 1973, Jones 1974, Kosasih \& Willetts 1975, Jayachandran et al. 1987) while the induced forcible ejection or 'puffing' of ascospores was observed and first photographed by Dickson \& Fisher (1923) followed by Harthill \& Underhill (1976). This puffing phenomenon, also observed in a variety of other ascomycetes, was studied by Ingold using Ascobolus crenulatus as a model. He developed a 'spore clock' apparatus and found that puffing could be induced by sudden changes in environmental conditions such as illumination after a dark period or a decrease in relative humidity or temperature (Ingold 1971). In addition, a continuous low background discharge of $A$. crenulatus ascospores was observed in saturated air. Similarly, Raynal (1990), in one of the few studies on spore discharge in Sclerotinia spp., also reported that there was continuous regular release of ascospores of $S$. trifoliorum in saturated air. Puffing of spore clouds by apothecia of $S$. sclerotiorum is easily induced by removing the lid of a sealed container containing apothecia kept in a saturated environment. However, if this puffing is due to a sudden decrease in humidity or pressure, then it may be questionable whether this 
phenomenon happens regularly in the field where sudden changes are unlikely to occur, although it has been observed on occasion (Newton \& Sequira 1972). Ascospore release in S. sclerotiorum is hence poorly understood with forcible ejection by puffing assumed to be the main type of spore discharge. This is perhaps because this is generally observed in the laboratory when contained apothecia are suddenly exposed to the air.

The information available on the effect of environmental factors on the survival of $S$. sclerotiorum ascospores is similarly scant, and only one study has tested a range of temperatures and humidities (Caesar \& Pearson 1983). Here, increasing temperature and humidity were shown to increase mortality such that most spores were killed within a few days in vitro. In the field, increased mortality of ascospores on bean leaves in the top of the canopy was positively correlated with hours above $21^{\circ} \mathrm{C}$.

Ascospore release and survival are therefore key stages in the lifecycle of S. sclerotiorum and hence information on environmental factors which affect these stages not only increases our understanding of the pathogen, but can also contribute to future disease control strategies.

The aim of the work reported here was to determine the effect of environmental conditions on both ascospore release and survival for a UK isolate of S. sclerotiorum. Firstly, the potential for S. sclerotiorum to release ascospores in a continuous manner rather than by puffing was investigated using a spore clock apparatus similar to that used by Ingold \& Marshall (1963). Secondly, the survival of ascospores was assessed in vitro using similar conditions to those tested by Caesar \& Pearson (1983) to determine whether a UK isolate of S. sclerotiorum responded in the same way.

\section{MATERIALS AND METHODS}

\section{Sclerotinia sclerotiorum isolate and production of sclerotia}

The isolate of Sclerotinia sclerotiorum used in this study (isolate 13; IMI 390053) was derived from sclerotia from diseased lettuce plants grown on a Cheshire peat soil (Turbary Moor Series). Original isolations were made by surface sterilising the collected sclerotia in $50 \% \mathrm{v} / \mathrm{v}$ sodium hypochlorite and $70 \%$ ethanol for 4 min with agitation followed by two washes in sterile distilled water (SDW) for $1 \mathrm{~min}$. Sclerotia were then bisected, placed on potato dextrose agar (PDA; Oxoid) and incubated for $4 \mathrm{wk}$ at $20^{\circ}$. Sclerotia formed in culture were then removed, stored at $10^{\circ}$ and used as a stock supply for all further cultures. Isolate 13 was selected from 20 original sclerotial isolations for its ability to produce uniform sclerotia in culture from which further sclerotia produced would germinate carpogenically to form apothecia under the appropriate conditions. To produce large numbers of sclerotia for apothecial production, two agar plugs (approx. $2 \mathrm{~mm}^{2}$ ) from the edge of four-day-old S. sclerotiorum colonies derived from stock sclerotia were used to inoculate sterile wheat grain ( $25 \mathrm{~g}$, wheat grain, $50 \mathrm{~g}$ water autoclaved at $121^{\circ}$ for $15 \mathrm{~min}$ ) in $500 \mathrm{ml}$ conical flasks. Flasks were shaken gently by hand twice a week to encourage formation of uniform sclerotia and prevent clumping of wheat grain and mycelium while incubating at $18^{\circ}$ (Sansford \& Coley-Smith 1992). After $4 \mathrm{wk}$, mature sclerotia were formed which were then incubated in the flasks at $4{ }^{\circ}$ for a further $4 \mathrm{wk}$, as a cold conditioning treatment, to ensure carpogenic germination and production of apothecia (Mylchreest \& Wheeler 1987, Sansford \& Coley-Smith 1992). After this period, sclerotia were wet sieved to recover those of $2-5 \mathrm{~mm}$, and the wheat grain floated off. Finally the sclerotia were dried in an air-flow cabinet overnight after which they were ready for use.

\section{Production of apothecia}

Pre-conditioned sclerotia (30) of isolate 13 were evenly placed on $100 \mathrm{~g}$ John Innes No 1 compost (GEM gardening, Accrington; pasteurised at $110^{\circ}$ for $30 \mathrm{~min}$ ) in clear plastic boxes $(600 \mathrm{ml}$; Malsar Kest, London). They were then covered with a further $30 \mathrm{~g}$ pasteurised compost $(0.5 \mathrm{~cm}$ depth), the boxes sealed and placed in a cooled glasshouse at $15-22^{\circ}$ or in a controlled environment cabinet at $15^{\circ}(12 \mathrm{~h}$ light/dark $)$. The compost moisture content was maintained at $30 \%(\mathrm{w} / \mathrm{w})$ by adding an appropriate amount of water initially and maintaining the weight of each box by further additions each week. Apothecia appeared after approx. $3-5 \mathrm{wk}$.

\section{Apparatus and methodology used to study ascospore release}

A spore clock apparatus similar to that used by Ingold \& Marshall (1963) was used in all ascospore release experiments (Fig. 1). A perspex rotating disc (A) housed in perspex casing with a removeable lid (B) was driven round by a small motor (C) over apothecia (D) placed in a detachable perspex chamber (E). Ascospores were trapped on acetate sheeting divided into 8 time sectors attached to the underside of the disc. The disc motor was turned on and off using a timer switch so that the disc could be rotated and a new time sector exposed to apothecia at regular specified intervals. At the end of experiments the acetate was removed and the ascospores removed from each time sector for counting. This was achieved by pipetting $0.5 \mathrm{ml}$ water onto the middle of the acetate sector and gently rubbing the area with the bulb of a $3 \mathrm{ml}$ plastic disposable pipette (Merck, Poole). The resulting spore suspension was then pipetted into a Bijou bottle $(5 \mathrm{ml})$ containing $1.5 \mathrm{ml}$ water. Ascospore numbers in the resulting $2 \mathrm{ml}$ suspension was then assessed using a Fuchs Rosenthal haemocytometer. Time sectors 7 or 8 on the acetate was always over the apothecia when the apparatus was 


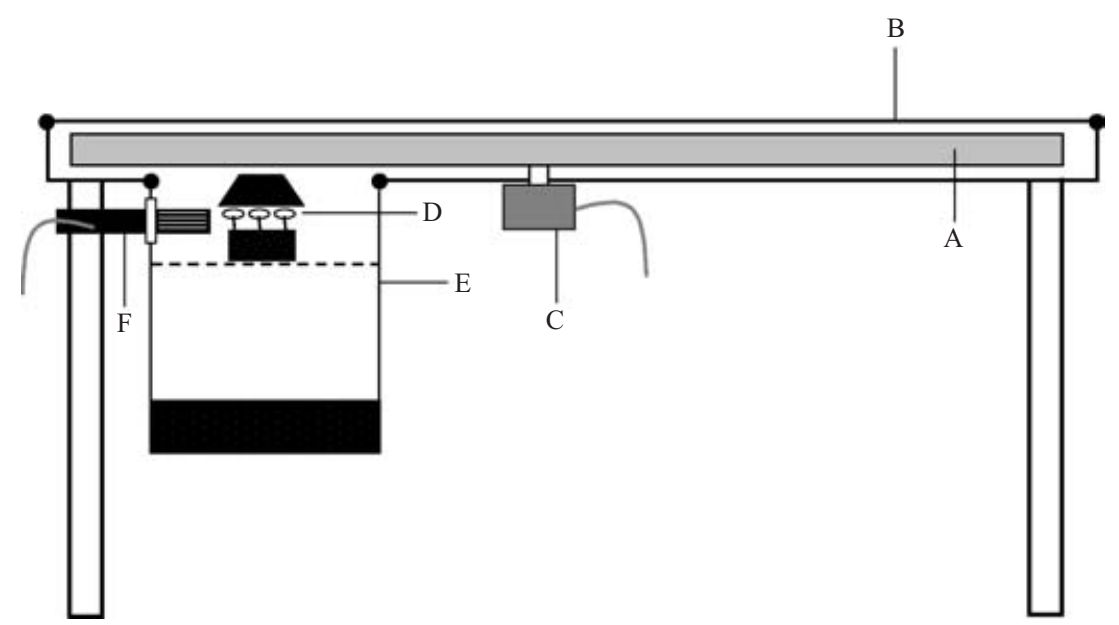

Fig. 1. Spore clock apparatus. A, perspex rotating disc; B, removeable perspex lid; C, motor; D, apothecia; E, detachable perspex chamber; F, humidity probe.

dismantled and the disc removed so that any further spore release through puffing would not affect the spore count in the other sectors. The chamber (E) which housed the apothecia had a slatted floor, below which was a reservoir which contained either water to maintain almost saturated air around the apothecia $(>90 \%$ rh), or a saturated salt solution to maintain a different $\mathrm{rh}$. The rh in the chamber was monitored using a humidity probe (Vaisala, Newmarket; F). The entire apparatus was placed in a controlled environment cabinet at $15^{\circ}$ where lighting duration could be controlled.

\section{Preparation of apothecia for ascospore release experiments}

Apothecia for use in the spore clock apparatus were produced in compost in a controlled environment cabinet at $15^{\circ}$ with a $12 \mathrm{~h}$ light and $12 \mathrm{~h}$ dark regime as described before. Initially, single sclerotia with three apothecia were selected for Experiments 1-3 (see below). These apothecia were 5-7 $\mathrm{mm}$ diam having just reached maturity. The cap was fully formed but not crenullated. In order to increase potential ascospore release and overcome the problem that three apothecia from a single sclerotium were often of different maturity, subsequent experiments used larger single apothecia $(8-10 \mathrm{~mm}$ diam) from individual sclerotia. These apothecia were more mature and the caps were crenellated. Selected sclerotia with apothecia were embedded in damp sand in a clear plastic round 'polypot' (4 cm diam, $3.5 \mathrm{~cm}$ deep; Kartell Plastics UK, Cambridge) and covered with another inverted polypot. Apothecia were then kept for $24 \mathrm{~h}$ in this condition under the same (synchronous) $12 \mathrm{~h}$ light regime as used for the spore clock apparatus. Just before use in experiments, spore release by puffing was induced in the apothecia at the end of a light period by removing the inverted polypot lid. Apothecia were then ready for use and transferred to the spore clock apparatus in the polypots. Those apothecia not releasing a visible spore cloud were rejected.

\section{Experiments on ascospore release}

Effect of light regime

The first set of four experiments investigated the effect of light regime on ascospore release from apothecia of Sclerotinia sclerotiorum at $15^{\circ}$ and $90-95 \%$ rh. Each experiment was repeated three times (Table 1). Experiment 1 was set up to determine if ascospores were released only during an $8 \mathrm{~h}$ light period. Three apothecia attached to a single sclerotium were exposed to a $12 \mathrm{~h}$ dark $12 \mathrm{~h}$ light regime but with time sectors rotated every 16 and $8 \mathrm{~h}$ (Fig. 2a). Initially, the apothecia were placed in the apparatus in the dark (acetate time sector 1) and the disc rotated to the next sector after $16 \mathrm{~h}$. Thereafter the apothecia was exposed to acetate time sector 2 for $8 \mathrm{~h}$ (entirely in the light) and then to sector 3 for $16 \mathrm{~h}$ ( $4 \mathrm{~h}$ light $+12 \mathrm{~h}$ dark) and so on. Hence, time sectors 2, 4 and 6 were exposed entirely in the light $(8 \mathrm{~h})$ and sectors 3 and 5 to $4 \mathrm{~h}$ light and $12 \mathrm{~h}$ dark. The experiment was stopped at the end of the light period after $72 \mathrm{~h}$ (time sector 6). The same set-up was used for experiments 2 and 3 (Fig. $2 a$, Table 1) except that the light regimes were continuous light and continuous dark repectively. The disc was rotated at the same times so that time sectors were exposed for 8 or $16 \mathrm{~h}$ for comparison with Experiment 1. At the end of each experiment, ascospores were removed from each acetate time sector and counted using a haemocytometer as described before. Experiment 4 again tested the effects of a $12 \mathrm{~h}$ light and $12 \mathrm{~h}$ dark but with synchronous movement of the acetate time sectors on the rotating disc (Fig. 2b). Hence, each sector was exposed to apothecia for either $12 \mathrm{~h}$ entirely in the dark or $12 \mathrm{~h}$ entirely in the light. For this experiment, three apothecia attached to three separate sclerotia of 
Table 1. Summary of treatments in experiments carried out using the spore clock apparatus.

\begin{tabular}{|c|c|c|c|c|c|c|}
\hline $\begin{array}{l}\text { Experiment } \\
\text { no. }\end{array}$ & Light regime & $\begin{array}{l}\mathrm{rh} \\
(\%)\end{array}$ & $\begin{array}{l}\text { Exposure time } \\
\text { in each acetate } \\
\text { time sector }(\mathrm{h})\end{array}$ & $\begin{array}{l}\text { No. apothecia/ } \\
\text { no. sclerotia used }\end{array}$ & $\begin{array}{l}\text { Expt } \\
\text { duration } \\
\text { (h) }\end{array}$ & $\begin{array}{l}\text { Spore release } \\
\text { assessment } \\
\text { method }\end{array}$ \\
\hline 1 & 12 h light/dark & $90-95$ & 8 or 16 & $3 / 1$ & 72 & Count \\
\hline 2 & continuous dark & $90-95$ & 8 or 16 & $3 / 1$ & 72 & Count \\
\hline 3 & continuous light & $90-95$ & 8 or 16 & $3 / 1$ & 72 & Count \\
\hline 4 & 12 h light/dark & $90-95$ & 12 & $3 / 3$ & 84 & Count \\
\hline 5 & 12 h light/dark & $65-75$ & 24 & $5 / 5$ & 168 & Visual \\
\hline 6 & $12 \mathrm{~h}$ light/dark & $90-95$ & 24 & $5 / 5$ & 168 & Visual \\
\hline
\end{tabular}
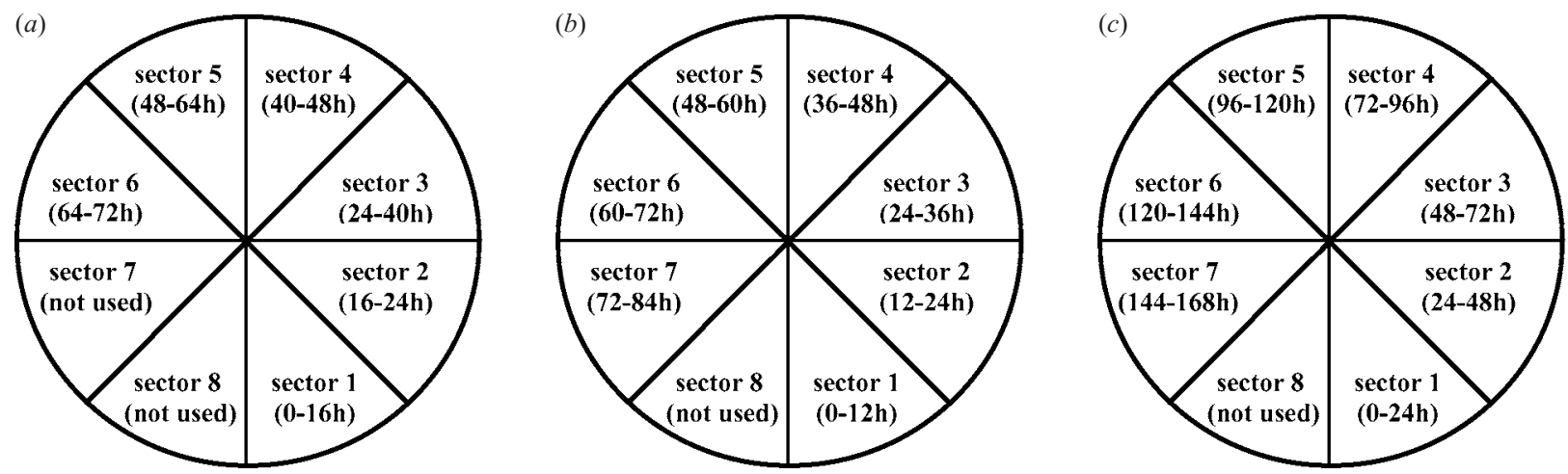

Fig. 2. Periods of apothecial exposure to acetate sectors attached to the perspex rotating disc from the spore clock apparatus for different experiments: (a) Experiments 1-3, (b) Experiment 4, and (c) Experiments 5-6. In each experiment, acetate was attached to the underside of the disc and divided into 8 sectors (1-8) as shown. The chamber containing apothecia (see Fig. 1, E) was completely covered by acetate sector 1 at the start of each experiment and subsequently rotated to give the following exposure times: $a$ (Experiments 1-3); acetate sectors 1, 3 and 7 exposed for $16 \mathrm{~h}$ and sectors 2,4 and 6 for $8 \mathrm{~h}$. $b$ (Experiment 4); each acetate sector exposed for $12 \mathrm{~h}$ and $c$ (Experiments 4 and 5); each acetate sector exposed for $24 \mathrm{~h}$. The light regime used in each experiment is shown in Table 1.

S. sclerotiorum were placed in the spore clock apparatus chamber in single poly pots. The experiment was stopped at the end of the dark period after $84 \mathrm{~h}$ (time sector 7).

\section{Effect of relative humidity}

Experiment 5 tested whether ascospores were released at rh levels below almost saturated air (90-95\% rh) at $15^{\circ}$. A $12 \mathrm{~h}$ light and $12 \mathrm{~h}$ dark regime was used with movement of the time sectors on the rotating disc every $24 \mathrm{~h}$ (Fig. 2c). The spore clock apparatus reservoir contained a saturated salt solution which maintained the apothecia at $65-70 \% \mathrm{rh}$ as measured by the humidity probe. Five apothecia from individual sclerotia were placed in the chamber (three in one polypot and two in another) and the experiment terminated at the end of the dark period after $168 \mathrm{~h}$ ( $7 \mathrm{~d}$, time sector 7). Instead of removing spores from the acetate at the end of the experiment and counting, spore release in each acetate time sector was assessed visually for each of the five apothecia. This was a quicker method of determining whether there were large differences in spore discharge between treatments. The following score system was used: 0 , no visible release; 1 , very light spore release (just visible); 2, light spore release; 3 , average spore release; 4 , heavy spore release. The experiment was repeated 3 times. To compare ascospore release from Experiment 5 with release at $90-95 \%$ rh, Experiment 6 was set up in the same way but with water in the apparatus reservoir to maintain saturated air (90-95\% rh) over the apothecia. Ascospore release was then assessed using the same visual scale.

\section{Collection of ascospores and spore survival studies}

For spore survival studies, ascospores were first obtained by trapping them on acetate sheets. The acetate was rubbed with a cloth to create a static charge and then held over a plastic box containing mature apothecia. When the box lid was removed, the resulting spore cloud impacted onto the acetate resulting in a monolayer of ascospores. In spore survival experiments, these acetate sheets were taped to the lids of clear plastic boxes $(600 \mathrm{ml}$; Malsar Kest) containing $150 \mathrm{ml}$ of various saturated salt solutions in order to create rh levels within each box. Six rh levels were tested in the range 33-96\% at temperatures of 3, 5, 15, 20,25 and $30^{\circ}$ in a first experiment and 5, 10, 15, 20, 25 and $30^{\circ}$ in a repeat experiment. The rh in each box was measured using a probe (Rotronic Instruments, Crawley) as the target $\mathrm{rh}$ varied with temperature 

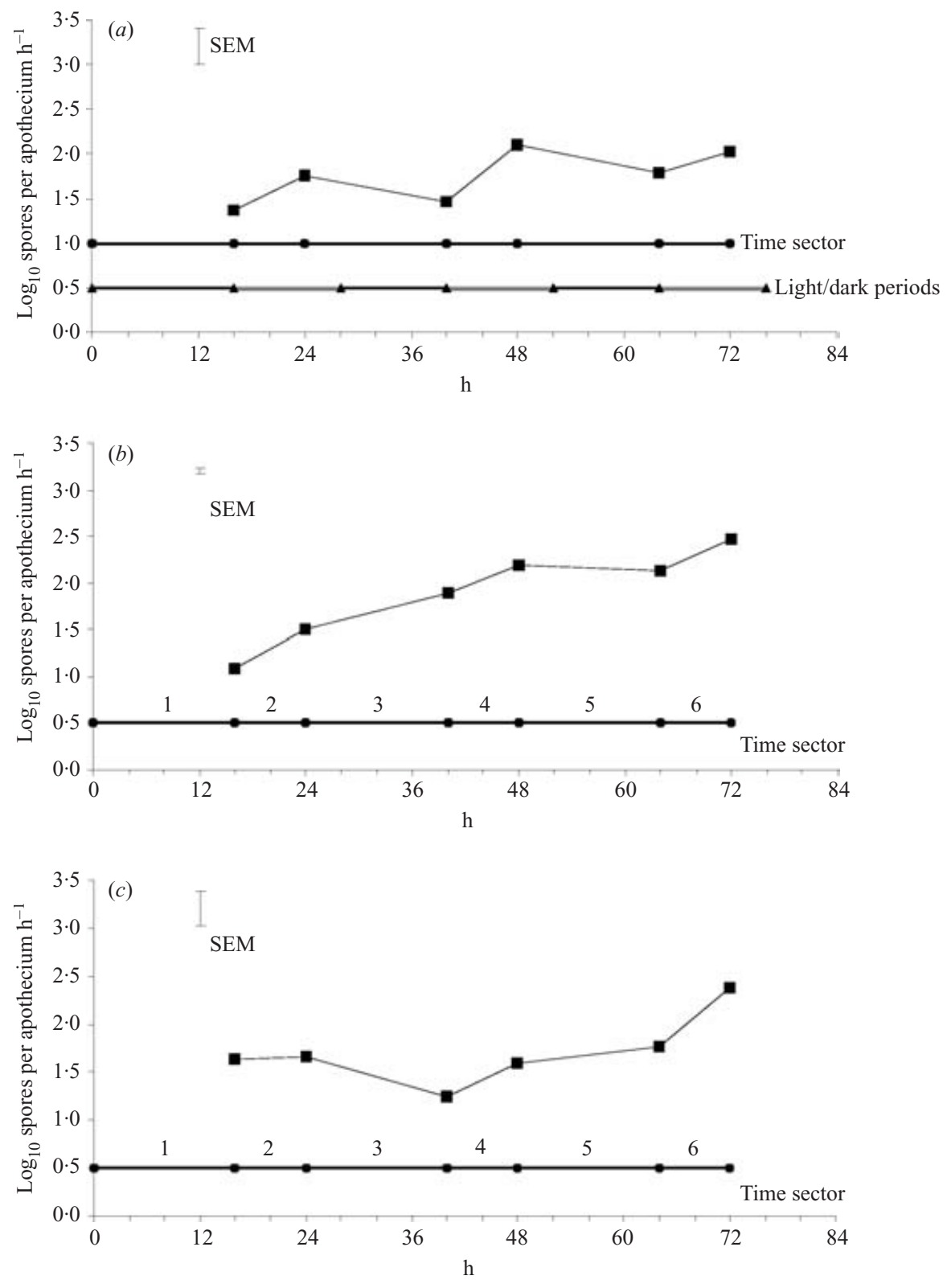

Fig. 3. Effect of different light regimes on rate of spore release from three apothecia from a single sclerotia of Sclerotinia sclerotiorum at $90-95 \% \mathrm{rh}$ and $15^{\circ} \mathrm{C} . a, 12 \mathrm{~h}$ light/dark; $b$, continuous light; $c$, continuous dark. Data are means of three experiments and represent the rate of spore release $\left(\log _{10}\right.$ spores per apothecium $\left.h^{-1}\right)$ for each of the $8 \mathrm{~h}$ or $16 \mathrm{~h}$ time periods shown. SEM, standard error of the difference between the means derived from ANOVA.

(Winston \& Bates 1960) and between experiments. To test spore viability at intervals, a small piece of acetate (approx. $1 \mathrm{~cm}^{2}$ ) was cut out from each temperature/ humidity treatment sheet and placed face down with $0.5 \mathrm{ml} \mathrm{SDW}$ on a PDA plate. The acetate piece was then gently spread around the plate with the water to remove spores. Germination of ascospores was then assessed under the microscope $(\times 100)$ after incubating plates at $20^{\circ}$ for $16 \mathrm{~h}$. A spore was considered to have germinated if one or more germ tubes was longer than half the spore length. For each humidity/temperature combination, 100 spores were assessed from three random areas on each PDA plate. Experiment 1 was terminated after $16 \mathrm{wk}$ and Experiment 2 after $21 \mathrm{wk}$.

\section{Statistical Analyses}

In the ascospore release experiments, spore count per apothecium for each acetate time sector was calculated and converted to a rate of release per apothecium $\mathrm{h}^{-1}$. Rates of spore release were then transformed to logarithms. Analyses of variance (ANOVA) were then performed on these data or visual scores treating the same time sectors from each of the three repeat experiments as replicates. Standard error of the difference between the means (SEM) derived from ANOVA was calculated. For the ascospore survival experiments mean percentage germination was calculated at each assessment time for each of the temperature/humidity 


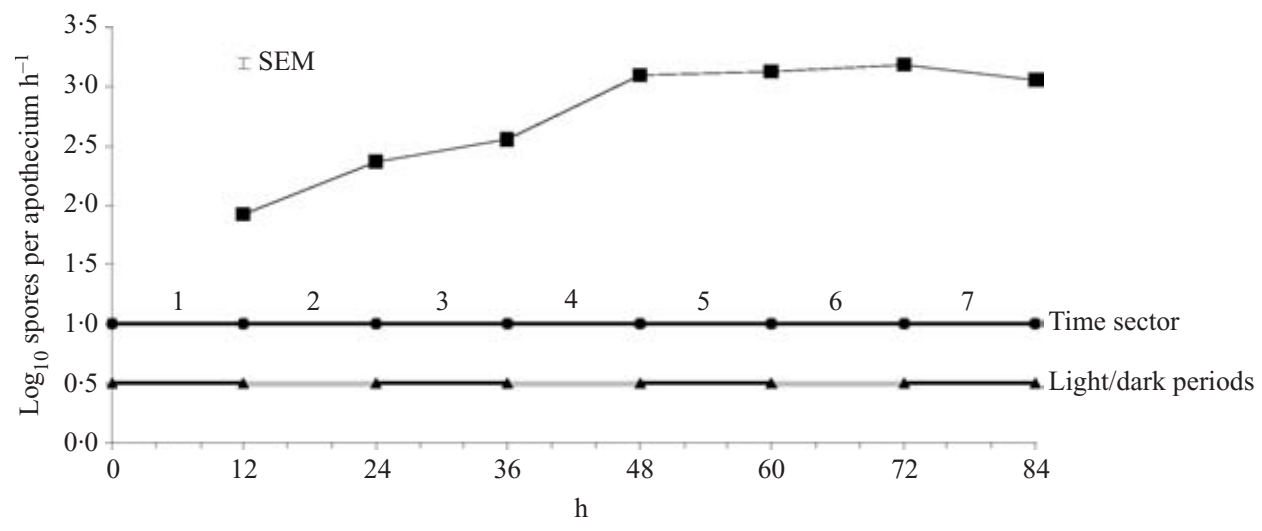

Fig. 4. Effect of $12 \mathrm{~h} \mathrm{light/dark} \mathrm{regime} \mathrm{on} \mathrm{rate} \mathrm{of} \mathrm{spore} \mathrm{release} \mathrm{from} \mathrm{three} \mathrm{apothecia} \mathrm{from} \mathrm{three} \mathrm{sclerotia} \mathrm{of} \mathrm{Sclerotinia}$ sclerotiorum at $90-95 \% \mathrm{rh}$ and $15{ }^{\circ} \mathrm{C}$. Data are means of three experiments and represent the rate of spore release (log $\log _{10}$ spores per apothecium $\mathrm{h}^{-1}$ ) for each of the $12 \mathrm{~h}$ periods shown. SEM, standard error of the difference between the means derived from ANOVA.

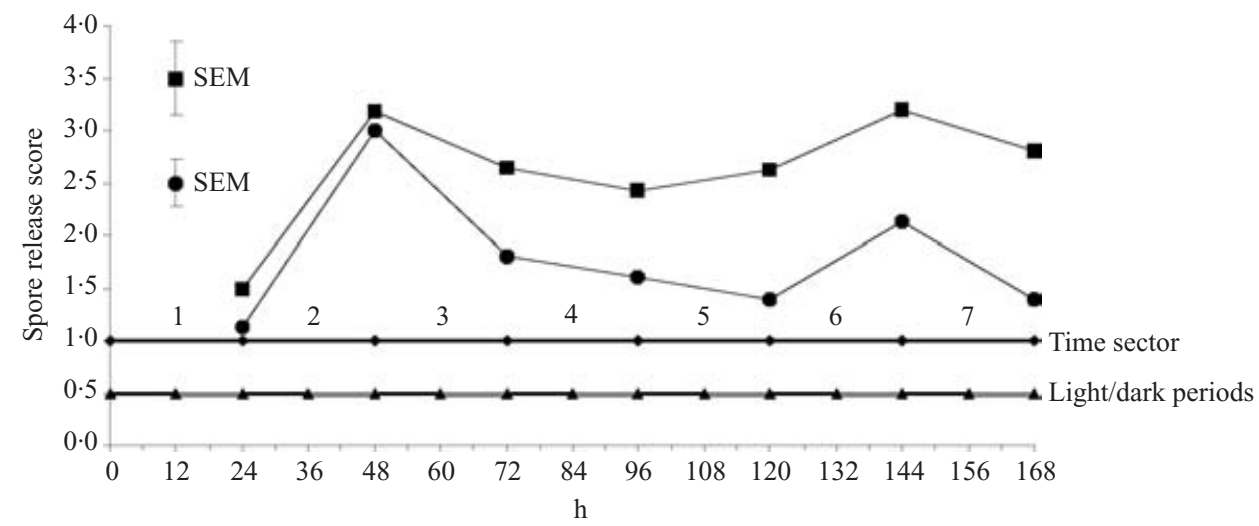

Fig. 5. Effect of humidity on spore release from five apothecia from five sclerotia of Sclerotinia sclerotiorum at $15^{\circ} \mathrm{C}$ in a $12 \mathrm{~h}$ light/dark regime: $\boldsymbol{\square}, 90-95 \% \mathrm{rh} ; \bullet, 65-75 \% \mathrm{rh}$. Data are means of three experiments and represent spore release score per apothecium in each of the $24 \mathrm{~h}$ time periods shown. SEM, standard error of the difference between the means derived from ANOVA.

treatments. Time to $50 \%$ mortality was calculated for each treatment by interpolation between appropriate time periods.

\section{RESULTS}

\section{Effect of light regime on ascospore release}

In saturated air $(90-95 \% \mathrm{rh})$ there was continuous ascospore release over $72 \mathrm{~h}$ at $15^{\circ}$ whether apothecia from a single sclerotium were exposed to fluctuating light and dark (Experiment 1; Fig. 3a), continuous light (Experiment 2; Fig. 3b) or continuous dark (Experiment 3; Fig. 3c). For all the light regimes there was a significant increase in the rate of spore release $(P \leqslant 0.05)$ between the first time sector $(16 \mathrm{~h})$ and the last $(72 \mathrm{~h})$ with a range of 10-316 ascospores released per apothecium $\mathrm{h}^{-1}$. When apothecia from individual sclerotia were exposed to acetate time sectors for $12 \mathrm{~h}$ synchronised in the 12 light/dark regime over $84 \mathrm{~h}$ at $15^{\circ}$ and $90-95 \% \mathrm{rh}$, there was again release in both the light and dark periods (Experiment 4; Fig. 4). The rate of ascospore release also increased significantly
$(P \leqslant 0.05)$ between the first time sector $(12 \mathrm{~h})$ and the last ( $84 \mathrm{~h})$ with a range of 100-1600 ascospores released per apothecium $\mathrm{h}^{-1}$. This confirmed that ascospore discharge was not confined to light or dark periods.

\section{Effect of relative humidity on ascospore release}

In both saturated air (90-95\% rh) and at 65-75\% rh, apothecia released ascospores continuously at $15^{\circ}$ in the $12 \mathrm{~h}$ light and dark regime (Experiments 5 and 6; Fig. 5). For both humidity levels, there was an initial significant increase $(P \leqslant 0.05)$ in spore number score after $36 \mathrm{~h}$ followed by regular release. However, during the $168 \mathrm{~h}(7 \mathrm{~d})$ duration of the experiment however there was a significant decline in the spore number score between $36 \mathrm{~h}$ and $168 \mathrm{~h}$ for apothecia at $65-75 \%$ rh $(P \leqslant 0.05)$, but this was not observed for apothecia at $90-95 \%$ rh.

\section{Effect of temperature and humidity on ascospore survival}

Ascospore survival at temperatures below $15^{\circ}$ was consistently high irrespective of rh (data not shown). 

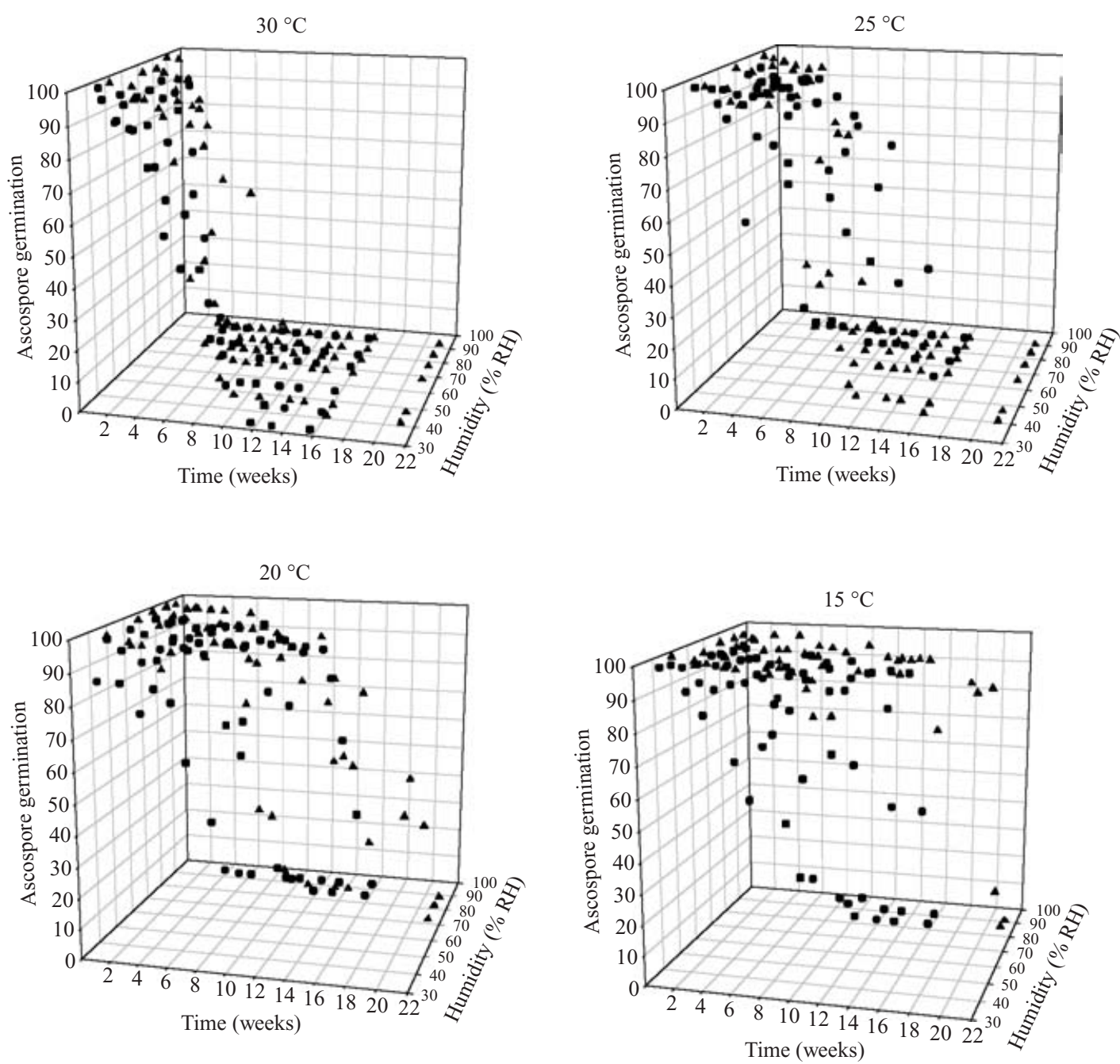

Fig. 6. Effect of humidity on Sclerotinia sclerotiorum ascospore viability (as measured by $\%$ germination) at $15-30{ }^{\circ} \mathrm{C}$. Data plotted are from two experiments ( $\boldsymbol{\square}$, Experiment $1 ; \boldsymbol{\Delta}$, Experiment 2). There was little decrease in viability at temperatures below $15^{\circ}$ (see Results).

Briefly, at temperatures of 3 and $5^{\circ}$, ascospore germination was $80 \%$ or above over the $16 \mathrm{wk}$ of Experiment 1, except at the highest rh tested for each temperature, which was 94 and $96 \%$ rh respectively. For these rh values, the time to $50 \%$ mortality was $9.5 \mathrm{wk}$ at $3^{\circ}$ and $6.6 \mathrm{wk}$ at $5^{\circ}$. However, in Experiment 2 , ascospore germination was $80 \%$ or above for all rhs tested at 5 and $10^{\circ}$, but the highest final rh values achieved were $91 \%$ and $93 \%$ respectively. For temperatures of $15^{\circ}$ and above, high humidity combined with increasing temperature reduced ascospore survival (Fig. 6). For rh values above $70 \%$, at least $50 \%$ mortality was observed at $15,20,25$ and $30^{\circ}$ by the end of the experiments. At $30^{\circ}, 50 \%$ of spores were killed within 2-3 wk for $\mathrm{rh}>80 \%$ while at $40-70 \% \mathrm{rh}, 50 \%$ mortality occurred after $4-6$ wk (Fig. 7). At $25^{\circ}, 50 \%$ mortality occurred at $2-7 \mathrm{wk}$ at $80-93 \%$ rh and $8-15$ wk at $40-70 \%$ rh. At 20 and $15^{\circ}$, few spores were killed below $60 \%$ rh. $50 \%$ mortality occurred at $15-18 \mathrm{wk}$ at $75 \% \mathrm{rh}$ and after $3 \mathrm{wk}$ at $92 \% \mathrm{rh}$. Although Figs 6-7 clearly show that both final ascospore viability and rate of loss of viability are related both to temperature and humidity, we were unable to derive a model to describe these relationships satisfactorily. This was in part due to $50 \%$ mortality being not reached for many of the temperature and humidity treatments for the duration of the experiments.

\section{DISCUSSION}

This is the first time that continual discharge of Sclerotinia sclerotiorum ascospores has been quantified in the laboratory, and the results showed that spore release occurred both in light and dark. The greater rates of ascospore release per apothecium were observed for more mature apothecia with crenullated cups and for experiments with a single apothecium on an individual sclerotium. Raynal (1990) also observed greater spore release in $S$. trifoliorum for larger apothecia. In addition, Raynal calculated that an apothecium of S. trifoliorum could release up to $5 \times 10^{6}$ spores over its lifetime of $20 \mathrm{~d}$ at $15^{\circ}$ while Abawi \& Grogan (1979) report that $S$. sclerotiorum apothecia may release up to 

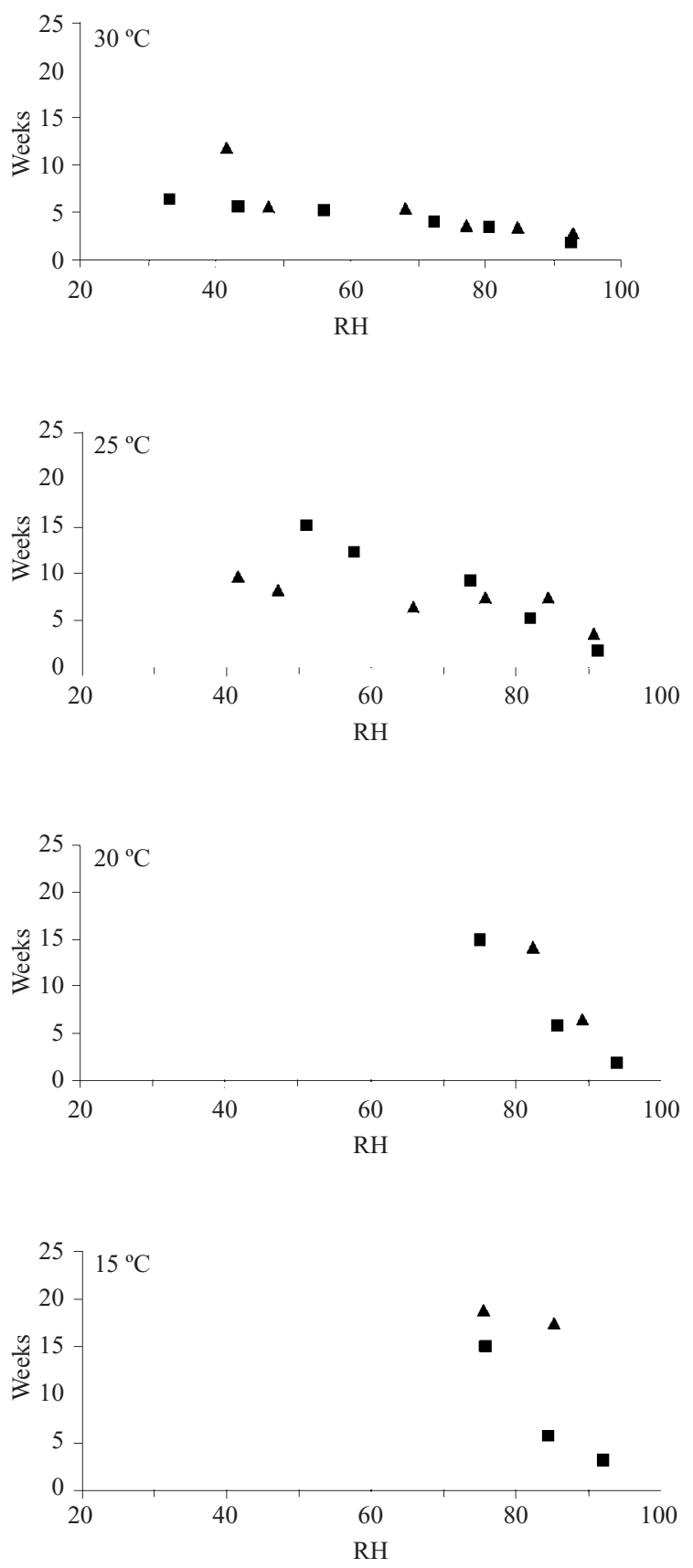

Fig. 7. Effect of humidity on time (weeks) to $50 \%$ Sclerotinia sclerotiorum ascospore mortality at $15-30{ }^{\circ} \mathrm{C}$. Data plotted are from two experiments $(\boldsymbol{\square}$, Experiment $1 ; \boldsymbol{\Delta}$, Experiment 2). Data is missing for temperature/humidity combinations where ascospore mortality did not fall below $50 \%$ (low temperature, low rh).

$3 \times 10^{7}$ ascospores. In comparison, at the maximum rate of 1600 ascospores $\mathrm{h}^{-1}$ observed for S. sclerotiorum apothecia in this study, corresponds to a release of $7.6 \times 10^{5}$ spores over $20 \mathrm{~d}$.

Ascospore release did not decrease during dark periods in our experiments and this is in contrast to some other ascomycetes such as Ascobolus crenulatus where although there is a steady 'background' discharge in the dark, levels of spore release are much greater in the light (Ingold 1971). Raynal (1990) also reported that light was more conducive to $S$. trifoliorum ascospore release than dark at $15^{\circ}$ although no data were presented. Ascospore release by S. sclerotiorum or $S$. trifoliorum in the field also shows a diurnal distribution pattern with peak levels occurring in the middle of the day (Harthill 1980, Raynal 1990, McCartney \& Lacey 1991). Harthill (1980) suggested that this was because ascospore discharge is only initiated in light although the laboratory data to support this was not presented. As this study showed that large numbers of ascospores could be discharged in the dark, it is most likely that the diurnal pattern of release is caused by an increase in temperature during the day rather the effect of light itself, as suggested by Raynal (1990). Indeed, spore discharge is weak in S. trifoliorum and S. sclerotiorum at 5-10 ${ }^{\circ}$ (Newton \& Sequeira 1972, Raynal 1990) and preliminary experiments with the spore clock used in this study have also found increased ascospore discharge at $20-25^{\circ}$ compared to $15^{\circ}$. This suggests that at higher temperatures there is a faster maturation rate of asci within the cup of the apothecium and hence more available for release. As well as affecting ascospore release directly, temperature also affects the longevity of S. sclerotiorum and S. trifoliorum apothecia (Newton \& Sequeira 1972, Raynal 1990) with spore discharge in $S$. trifoliorum lasting over a month at $5-10^{\circ}, 3 \mathrm{wk}$ at $15-20^{\circ}$ and less than $10 \mathrm{~d}$ at $25^{\circ}$ (Raynal 1990).

Previous laboratory observations of ascospore release by $S$. sclerotiorum or S. trifoliorum have always been in saturated air (Newton \& Sequeira 1972, Raynal 1990) but this study has shown for the first time that continuous release of $S$. sclerotiorum ascospores occurs in non-saturated air at $65-75 \% \mathrm{rh}$. High rh periods at night followed by decreasing rh the following day may therefore be unnecessary for release of ascospores in the field as suggested by McCartney \& Lacey (1990). However, the lower rh level tested in this study did cause a decline in ascospore release over $7 \mathrm{~d}$ compared to saturated air $(90-95 \% \mathrm{rh})$ indicating that the longevity of the functioning apothecium was affected.

The survival of $S$. sclerotiorum ascospores was reduced at high temperature and rh, a trend also observed by Caesar \& Pearson (1983). Increasing rh has been shown to decrease $S$. sclerotiorum spore survival elsewhere (Partyka \& Mai 1962, Abawi \& Grogan 1975), but ascospores survived much longer in our experiments than in any of these other studies. For instance, at 25 and $30^{\circ}$, Caesar \& Pearson reported that ascospores exposed to $>60 \%$ rh survived between 2-8 d with $50 \%$ mortality within $4-5 \mathrm{~d}$. This compares to $2-3$ wk at $30^{\circ}$ in this study. Similarly, at 5 and $10^{\circ}$, Caesar \& Pearson reported that ascospores exposed to $>80 \%$ rh did not survive beyond $16 \mathrm{~d}$, whereas in our experiments viability was maintained at these temperatures for the 16 or $21 \mathrm{wk}$ duration of the experiments. This discrepancy may be due to the origin of the $S$. sclerotiorum isolate used in each study. Certainly $S$. sclerotiorum is genetically variable (Carpenter, Frampton \& Stewart 1999) and carpogenic germination of 
sclerotia of isolates of different geographic origin have been shown to have different temperature optima (Huang \& Kozub 1991). In addition, the rh values reported by Caesar \& Pearson (who also used saturated salt solutions) were not measured independently. However, small variations in rh values in the experiments by Caesar \& Pearson (1983) would not account for the difference in spore survival with our study. $S$. sclerotiorum ascospore survival is also affected adversely by uv light (Caesar \& Pearson 1983) so results from this study would not necessarily be directly transferable to the field. However, germination of ascospores in free water and subsequent infection can occur between 10 and $25^{\circ}$ (Abawi \& Grogan 1975, Phillips 1994, Clarkson, Whipps \& Young 2001) on plants and also at relative humidities approaching saturation (Grogan \& Abawi 1975). In addition, the survival of germinated ascospores and appressoria on or in plant tissue may be greater than ungerminated spores (Grogan \& Abawi 1975). Therefore, it is unlikely that spore survival is a limiting factor to infection by $S$. sclerotiorum in the UK as conditions conducive to spore germination would occur most days (or nights) within the growing season of susceptible crops.

The factors affecting the availability of viable ascospore inoculum in the field from apothecia of S. sclerotiorum in the field are complex. From this and other studies, ascospore release by $S$. sclerotiorum in the field has the potential to take place during the night or day over a range of conditions in a continuous manner during the life of the apothecium. More work though is required to assess the effect of fluctuating temperature and rh on ascospore discharge and also to investigate under what field conditions, puffing of apothecia may occur.

The balance between greater ascospore discharge at $20-25^{\circ}$ in S. sclerotiorum (Newton \& Sequeira 1972), with a corresponding decrease in apothecial longevity (as observed with S. trifoliorum; Raynal 1990), may be the key factor influencing the inoculum potential at different times of year (providing apothecia are present). Hence, in the Summer, large numbers of spores may be released over short periods of time as apothecia quickly die, whereas in the cooler Spring and Autumn months, fewer spores would be released but over more extended periods of time as apothecia survive longer. Further work is therefore required to assess the effect of temperature and humidity on apothecial longevity not addressed in the short-term experiments described here. The effect of soil moisture which, when high, may also help maintain a functioning apothecium (Raynal 1990) must also be considered.

Temperature and soil moisture are key factors affecting carpogenic germination of S. sclerotiorum sclerotia to produce apothecia (Phillips 1987, Clarkson et al. 2001) and current work is addressing how this data may be used in predicting the appearance of apothecia in the field. This information, combined with the knowledge of conditions governing ascospore release and survival, may be useful in assessing when there are periods of high inoculum potential in the field. Fungicide sprays could then be targeted for these high risk periods leading to a more rational approach to chemical control of Sclerotinia disease.

\section{REFERENCES}

Abawi, G. S. \& Grogan, R. G. (1975) Source of primary inoculum and effects of temperature and moisture on infection of beans by Whetzelinia sclerotiorum. Phytopathology 65: 300-309.

Abawi, G. S. \& Grogan, R. (1979) Epidemiology of diseases caused by Sclerotinia species. Phytopathology 69: 899-903.

Bardin, S. D. \& Huang, H. C. (2001) Research on biology and control of Sclerotinia diseases in Canada. Canadian Journal of Plant Pathology 23: 88-98.

Boland, G. J. \& Hall, R. (1987) Epidemiology of white mold of white bean in Ontario. Canadian Journal of Plant Pathology 9: 218-224.

Boland, G. J. \& Hall, R. (1994) Index of plant hosts of Sclerotinia sclerotiorum. Canadian Journal of Plant Pathology 16: 93-108.

Caesar, A. J. \& Pearson, R. C. (1983) Environmental-factors affecting survival of ascospores of Sclerotinia sclerotiorum. Phytopathology 73: 1024-1030.

Carpenter, M. A., Frampton, C. \& Stewart, A. (1999) Genetic variation in New Zealand populations of the plant pathogen Sclerotinia sclerotiorum. New Zealand Journal of Crop and Horticultural Science 27: 13-21.

Clarkson, J. P., Whipps, J. M. \& Young, C. S. (2001) Epidemiology of Sclerotinia sclerotiorum on lettuce. In Proceedings of Sclerotinia 2001 - The XI International Sclerotinia Workshop, York, UK, July 2001 (C. S. Young \& K. J. D. Hughes, eds): 79. Central Science Laboratory, York.

Dickson, L. F. \& Fisher, W. R. (1923) A method of photographing spore dispersal from apothecia. Phytopathology 13: 30-32.

Grogan, R. G. \& Abawi, G. S. (1975) Influence of water potential on growth and survival of Whetzelina sclerotiorum. Phytopathology 65: $122-138$.

Harthill, W. F. T. (1980) Aerobiology of Sclerotinia sclerotiorum and Botrytis cinerea spores in New Zealand tobacco crops. New Zealand Journal of Agricultural Research 23: 259-262.

Harthill, W. F. T. \& Underhill, A. P. (1976) Puffing in Sclerotinia sclerotiorum and S. minor. New Zealand Journal of Botany 14: 355-358.

Huang, H. C. \& Kozub, G. C. (1991) Temperature requirements for carpogenic germination of sclerotia of Sclerotinia sclerotiorum isolates of different geographic origin. Botanical Bulletin of Academia Sinica 32: 279-286.

Ingold, C. T. (1971) Fungal Spores: their liberation and dispersal. Oxford University Press, London.

Ingold, C. T. \& Marshall, B. (1963) Further observations on light and spore discharge in certain pyrenomycetes. Annals of Botany 27: 481-491.

Jayachandran, M., Willetts, H. J. \& Bullock, S. (1987) Light and scanning electron-microscope observations on apothecial development of Sclerotinia sclerotiorum, Sclerotinia trifoliorum and Sclerotinia minor. Transactions of the British Mycological Society 89: 167-178.

Jones, D. (1974) Ultrastucture of the stipe and apothecium of Sclerotinia sclerotiorum. Transactions of the British Mycological Society 63: $386-389$.

Kosasih, B. D. \& Willetts, H. J. (1975) Ontogenetic and histochemical studies of the apothecium of Sclerotinia sclerotiorum. Annals of Botany 39: 185-191.

McCartney, H. A. \& Lacey, M. E. (1991) The relationship between the release of ascospores of Sclerotinia sclerotiorum, infection and disease in sunflower plots in the United Kingdom. Grana 30: 486-492. 
Mylchreest, S. J. \& Wheeler, B. E. J. (1987) A method for inducing apothecia from sclerotia of Sclerotinia sclerotiorum. Plant Pathology 36: 16-20.

Newton, H. C. \& Sequeira, L. (1972) Ascospores as the primary infective propagule of Sclerotinia sclerotiorum in Wisconsin. Plant Disease 56: 798-802.

Partyka, R. E. \& Mai, W. F. (1962) Effects of environment and some chemicals on Sclerotinia sclerotiorum in laboratory and potato field. Phytopathology 52: 766-770.

Phillips, A. J. L. (1987) Carpogenic germination of sclerotia of Sclerotinia sclerotiorum: A review. Phytophylactica 19: 279-283.

Phillips, A. J. L. (1994) Influence of fluctuating temperatures and interrupted periods of plant-surface wetness on infection of beanleaves by ascospores of Sclerotinia sclerotiorum. Annals of Applied Biology 124: 413-427.
Raynal, G. (1990) [Kinetics of the ascospore production of Sclerotinia trifoliorum (Eriks) in growth chamber and under natural climatic conditions - practical and epidemiologic incidence.] Agronomie 10: 561-572. [In French.]

Saito, I. (1973) Initiation and development of apothecial stipe primordia in sclerotia of Sclerotinia sclerotiorum. Transactions of the Mycological Society of Japan 14: 343-351.

Sansford, C. E. \& Coley-Smith, J. R. (1992) Production and germination of sclerotia of Sclerotinia sclerotiorum. Plant Pathology 41 : 154-156.

Winston, P. W. \& Bates, D. H. (1960) Saturated solutions for control of humidity in biological research. Ecology 41: 232-237.

Corresponding Editor: E. D. Robson 